\title{
Efficacy and safety of the cyclooxygenase 2 inhibitors parecoxib and valdecoxib in patients undergoing coronary artery bypass surgery
}

Elisabeth Ott, MD, ${ }^{a, c}$ Nancy A. Nussmeier, MD, a,d Peter C. Duke, MD, ${ }^{a, e}$ Robert O. Feneck, MD, a,f R. Peter Alston, MD, ${ }^{\mathrm{e}, \mathrm{g}}$ Michael C. Snabes, MD, PhD, ${ }^{\mathrm{h}}$ Richard C. Hubbard, MD, ${ }^{\mathrm{h}}$ Ping H. Hsu, PhD, ${ }^{\mathrm{b}}$ Lawrence J. Saidman, MD, ${ }^{\mathrm{a}, \mathrm{h}, \mathrm{i}}$

Dennis T. Mangano, PhD, MD, ${ }^{a, b}$ for the Multicenter Study of Perioperative Ischemia (McSPI) Research Group and the Ischemia Research and Education Foundation (IREF) Investigators*

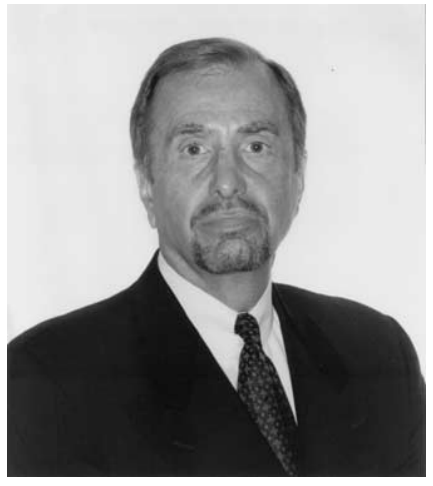

Dr Mangano

From the Ischemia Research and Education Foundation, San Francisco, Calif (P.H H., L.S., D.T.M.), the McSPI Research Group, San Francisco, Calif (E.O., N.N., P.D., R.F., P.A., L.S., D.T.M.), ${ }^{\mathrm{a}}$ the Departments of Anesthesiology at Ludwig-Maximilians University, Munich, Germany (E.O.), ${ }^{\mathrm{c}}$ the Texas Heart Institute, Houston, Texas (N.A.N.), ${ }^{\mathrm{d}}$ University of Manitoba Health Sciences Center, Winnipeg, Canada (P.C.D.), ${ }^{\mathrm{e}}$ Saint Thomas' Hospital, London, United Kingdom (R.O.F.), the Royal Infirmary of Edinburgh, Edinburgh, Scotland, United Kongdom (R.P.A.), ${ }^{\mathrm{g}}$ Stanford University Medical Center (L.S.), ${ }^{\mathrm{i}}$ Stanford, Calif, and Pharmacia Corporation, Skokie, Ill (M.C.S. and R.H.). ${ }^{\mathrm{h}}$

Received for publication June 26, 2002; revisions requested Aug 26, 2002; revisions received Oct 8, 2002; accepted for publication Oct 18, 2002.

Address for reprints: Dennis T. Mangano, $\mathrm{PhD}, \mathrm{MD}$, c/o Editorial Office, Ischemia Research and Education Foundation, 250 Executive Park Blvd, Suite 3400, San Francisco, CA 94134 (E-mail: dnmngn@aol.com).

*See Appendixes 1 and 2 for a complete list of the Investigators and Centers.

J Thorac Cardiovasc Surg 2003;125: 1481-92

Copyright $\odot 2003$ by The American Association for Thoracic Surgery

$0022-5223 / 2003 \$ 30.00+0$

doi:10.1016/S0022-5223(3)00125-9
Objective: Inhibition of cyclooxygenase 2 provides analgesia in ambulatory patients. We prospectively evaluated the safety and efficacy of a newly introduced cyclooxygenase 2 inhibitor in patients undergoing coronary artery bypass grafting surgery through a median sternotomy in a randomized clinical trial.

Methods: A total of 462 patients with New York Heart Association classes I to III who were less than 77 years of age and were from 58 institutions in the United States, Canada, Germany, and the United Kingdom participated in this multicenter, phase III, placebo-controlled, double-blind, randomized, parallel-group trial. Patients were allocated at a ratio of 2:1 to parecoxib/valdecoxib or standard care (control) groups, respectively. Intravenous study drug $(40 \mathrm{mg}$ ) was administered within 30 minutes after extubation and every 12 hours for a minimum of 3 days. Subsequently, oral treatment at a dose of $40 \mathrm{mg}$ every 12 hours was initiated and administered for a combined total of 14 days. Patient-controlled analgesia with morphine, oral opioids, or acetaminophen was available as required. Assessment of the analgesic efficacy of the study drug was primarily based on morphine and morphine equivalent use. Additional efficacy evaluations included daily pain intensity, patient and physician global evaluation of study medication, and pain effect on quality of life. Clinical adverse events were assessed by the principal investigator at each site from the time of the first dose through the 30-day postdosing period.

Results: Patients in the parecoxib/valdecoxib group received significantly less morphine or morphine equivalents than patients in the control group during the 0to 24-hour $(P=.009)$, 24- to 48-hour $(P=.017)$, 72- to 96-hour $(P=.002)$, 96to 120 -hour $(P=.004)$, and 120 - to 144 -hour $(P=.037)$ periods. Both patients $(P<.001)$ and physicians $(P<.001)$ evaluated the study medication as significantly better than control therapy. The modified Brief Pain Inventory questionnaire used in the oral dosing period detected significant improvements in the parecoxib/ valdecoxib treatment group in 6 of 8 domains tested (eg, current pain, worst pain, and mood) beginning on day 4 and continuing for at least 4 days. Although there were no differences between the groups in overall adverse events, serious adverse events occurred twice as frequently in parecoxib/valdecoxib-treated patients $(19.0 \%, 59 / 311$ patients) than in control patients $(9.9 \%, 15 / 151$ patients; $P=.015)$. Regarding individual serious adverse events, a greater incidence in sternal wound infection was found in the parecoxib/valdecoxib patients (10 [3.2\%]) versus control patients $(0[0 \%])(P=.035)$. The incidences of other individual serious adverse events, including cerebrovascular complications, myocardial infarction, and renal dysfunction, were proportionally greater but not significantly different between the groups.

Conclusions: In patients undergoing coronary artery bypass grafting surgery, the cyclooxygenase 2 inhibitor combination, parecoxib/valdecoxib, was effective for 
postoperative analgesia. However, the 14-day treatment regimen also was associated with an increased incidence of serious adverse events overall and sternal wound infections in particular. Therefore our study raises important concerns requiring their comprehensive evaluation in a large-scale trial before these cyclooxygenase 2 inhibitors are used in patients undergoing coronary artery bypass grafting surgery.

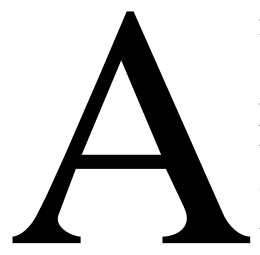

fter coronary artery bypass grafting (CABG), patients experience incisional pain associated with sternotomy, chest tube insertion, and leg vein excision. ${ }^{1}$ Opioids and nonsteroidal anti-inflammatory drugs (NSAIDs) are administered parenterally as analgesics in the early postoperative period to alleviate such pain. ${ }^{2}$ However, the efficacy of these analgesic drugs is limited by side effects that impede patient rehabilitation after surgical intervention. Opioids, such as morphine sulfate, can be associated, particularly in older patients, with respiratory depression, excessive sedation, and confusion, and parenteral NSAIDs, such as ketorolac, can be associated with gastrointestinal ulceration, renal dysfunction, and bleeding caused by platelet inhibition. ${ }^{3}$ Therefore development of new analgesics that are not only efficacious but also have an improved side-effect profile would enhance patient comfort and well-being and even reduce resource use costs.

In ambulatory patients and general surgical patients, among the newest approaches to acute pain control is selective inhibition of the cyclooxygenase 2 (COX-2) enzyme, which mediates inflammatory prostaglandin synthesis. ${ }^{4-6}$ Inhibiting the inducible COX-2 isoform results in desirable anti-inflammatory and analgesic effects, whereas nonselective inhibition of the constitutive COX-1 and COX-2 enzymes is associated with gastrointestinal, plateletrelated, renal, and other adverse side effects. ${ }^{7}$ Conventional NSAIDs nonspecifically inhibit both COX isoforms. ${ }^{8-11}$

Higher-risk populations have not been specifically studied in prior selective COX-2 inhibitor analgesia clinical trials, resulting in limited experience with efficacy and safety in these populations. Therefore we prospectively studied patients undergoing CABG surgery by using a new parenteral combined with oral COX-2 selective inhibitor.

\section{Methods}

\section{General Study Design}

This was a multicenter, double-blind, and controlled clinical trial, with the active study medication (parecoxib/valdecoxib) or standard care (control) randomized in a 2:1 ratio within each center. After institutional approval and written informed consent were obtained, 462 patients undergoing CABG were enrolled from 58 medical centers in the United States, Canada, Germany, and the United Kingdom between January and May 2000.
Preoperative inclusion criteria were age of less than 77 years, body mass index (BMI) of less than or equal to $40 \mathrm{~kg} / \mathrm{m}^{2}$, weight of greater than $55 \mathrm{~kg}$, left ventricular ejection fraction of greater than or equal to 35\%, and New York Heart Association class of I to III. In addition, in each patient the presence of adequately treated blood pressure and absence of psychologic illness were confirmed. Exclusion criteria were patients undergoing emergency surgery and those with a recent $(<48$ hours) myocardial infarction, insulin-dependent or uncontrolled diabetes (fasting blood sugar $>350 \mathrm{mg} / \mathrm{dL}$ or $19.4 \mathrm{mmol} / \mathrm{L}$ ), increased concentrations of liver enzymes (aspartate aminotransferase or alanine aminotransferase $>1.5$ of the upper limit of normal), creatinine level of greater than $1.5 \mathrm{mg} / \mathrm{dL}$ (or $133 \mu \mathrm{mol} / \mathrm{L}$ ), or any coagulopathy. Also excluded were patients with stroke or transient ischemic attack within 6 months and those with substance abuse (opioids, any other analgesics, or alcohol), allergy to nonsteroidal anti-inflammatory agents, or a history of gastric or duodenal ulcer.

Intraoperative exclusion criteria included a complicated intraoperative course, cardiopulmonary bypass time exceeding 3 hours, or insertion of an intra-aortic balloon pump. In the postoperative period and before randomization, patients were excluded from the study if they were receiving 3 or more inotropic infusions, had a symptomatic dysrhythmia, had new Q-wave myocardial infarction, had a cardiac index of less than $1.5 \mathrm{~L} / \mathrm{min}$, had a chest tube output of greater than $500 \mathrm{~mL}$ in a 2-hour period, had a temperature of less than $36^{\circ} \mathrm{C}$ or greater than $38^{\circ} \mathrm{C}$, had a urine output of less than $50 \mathrm{~mL} / \mathrm{h}$, had a hemoglobin level of less than $8 \mathrm{~g} / \mathrm{dL}$ (or 1.24 $\mathrm{mmol} / \mathrm{L}$ ), or had a serum creatinine level exceeding $1.2 \mathrm{mg} / \mathrm{dL}$ (or $106 \mu \mathrm{mol} / \mathrm{L}$ ) or $30 \%$ greater than the baseline value.

\section{Study Procedures Before Drug Administration}

Preoperative cardiac medications were continued until the time of surgical intervention. Anesthesia was induced by using fentanyl and/or midazolam, isoflurane, and a muscle relaxant for tracheal intubation. Anesthesia was maintained with isoflurane and/or propofol, fentanyl, midazolam and pancuronium in all institutions. Although the conduct of the anesthesia and surgical intervention was similar for each institution, no attempts were made to further standardize techniques. Cardiopulmonary bypass was used in $89 \%$ (411/462) of patients with hemodilution, mild-to-moderate hypothermia, and membrane oxygenators, with no difference between groups. In $11 \%$ (51/462) of patients, off-pump CABG was performed. For initial management in the intensive care unit, propofol, morphine, or midazolam for sedation and analgesia were administered at the discretion of the treating clinician. All patients in both study groups received aspirin (80-325 mg/d), starting by the time of the first dose of study medication. In each patient the trachea was extubated within 15 hours of surgical intervention. 
Subsequently, those meeting the inclusion and exclusion criteria were randomized.

\section{Administration of Parecoxib/Valdecoxib}

Intravenous administration of the study drug (40 mg of parecoxib or placebo) began within 30 minutes of extubation of the trachea immediately after a baseline pain assessment but before initiation of patient-controlled analgesia (PCA). The study drug was then administered intravenously every 12 hours and was continued for a minimum of 72 hours to allow uniform assessment of efficacy and safety over the first 3 days among all participating centers. All patients had access to intravenous morphine sulfate by means of PCA for supplemental pain medication starting immediately after tracheal extubation and continuing for at least 24 hours and thereafter at the discretion of the treating clinician. In addition to study-mandated treatments, all other medications required to manage a patient's individual care were permitted, with the exception of NSAIDs.

After 72 hours, if the patient were able to tolerate oral medication, the intravenous dosing scheme was changed to an enteral (oral) scheme, at which time either $40 \mathrm{mg}$ of valdecoxib or placebo was administered every 12 hours. Supplemental pain medication consisting of combinations of codeine $(30 \mathrm{mg})$ and acetaminophen (300 $\mathrm{mg}$ or $500 \mathrm{mg}$ ) in doses of 1 to 2 tablets every 4 to 6 hours was available to all patients and administered at their discretion. At the time of discharge from the hospital, each patient received the oral study medication and supplementary pain medication, with instructions to continue study-mandated treatment after hospitalization. The oral dosing period was scheduled to last from the end of intravenous dosing to day 14 .

\section{Evaluation of Analgesic Efficacy}

The primary measure for comparing efficacy of parecoxib/valdecoxib versus control was the amount of morphine sulfate (or morphine equivalents consumed). ${ }^{12-14}$ Additional assessments included a daily pain intensity score recorded as peak intensity on a 4-point categoric scale. A clinical investigator evaluated pain intensity daily for each day of treatment. Also, the peak pain intensity difference between maximum daily sternotomy pain and pretreatment sternotomy pain was calculated for each day of treatment.

At the time of transition from intravenous to oral drug administration, before hospital discharge, and on day 14 (study termination or sooner if premature termination occurred), physician and patient global assessments of the effects of the study medications were obtained. On discharge from the hospital, each patient received a patient diary to continue daily pain assessments. The diary included the modified Brief Pain Inventory, a validated instrument designed to evaluate the effect of pain on the patient's ability to perform daily living activities.

\section{Safety Assessment}

Safety was assessed on the basis of the occurrence of clinical adverse events (AEs) and serious adverse events (SAEs), as reported by the principal investigator at each site. AEs were judged to be serious if they resulted in a fatality or hospitalization or if the principal investigator believed that the event was life threatening or otherwise medically significant. The principal investigator at each study site also made a judgment as to whether there was a probable, uncertain, or lack of relationship of each AE to study treatment. When multiple episodes of the same AE were reported, the greatest known attribution was presented. All events occurring from the time of the first dose through the 30-day postdosing period were included. The World Health Organization Adverse Reaction Terminology dictionary ${ }^{15}$ was used to code the investigator's description of AEs, and the resulting primary terms were used in the calculation of incidence for comparative analysis. In addition to AE assessment, safety was evaluated on the basis of physical examination, measurement of vital signs, recording of electrocardiographs, and collection of blood samples for clinical laboratory measurements at the time of changing from intravenous to oral drug administration, before hospital discharge, and on day 14 (study termination or sooner if premature termination occurred).

\section{Statistical Analysis}

Efficacy. The proportion of patients who received opioids, including morphine PCA, during fixed time intervals was compared between treatment groups by using the Cochran-MantelHaenszel test stratified by country. Mean morphine consumption by means of PCA and total opioid (morphine equivalents) consumption were compared on the basis of time intervals by using an analysis of variance (ANOVA) with treatment and country as factors and with the time to first morphine dose as an additional factor when appropriate. Oral opioid use per day was recorded and compared between treatment groups by using a Wilcoxon test. No assumption was made for missing values in the primary efficacy variable (morphine consumption). Peak pain intensity difference was analyzed by using an ANOVA with treatment and country as factors and baseline pain intensity as a covariate. Except for the primary efficacy variable (morphine consumption), the approach of last observation carried forward was adopted to account for missing values. When multiple time periods were combined for presentation, the largest $P$ value among the combined periods was reported. The patient's and the physician's global evaluations of study medication at the time of transition from intravenous to oral administration, discharge from the hospital, and final visit were compared between treatment groups by using the Cochran-MantelHaenszel test stratified by country.

Safety. The incidences of both AEs and SAEs were compared between treatment groups by using the Fisher exact test, which provides a $P$ value for each comparison. Multiple logistic regression was used to evaluate potential risk factors for SAEs. The changes from baseline values in laboratory tests and vital signs were compared between treatment groups with a 1-way ANOVA. The intent-to-treat cohort was used in all safety and efficacy analyses of morphine consumption. The intent-to-treat cohort consisted of all patients who received a dose of study medication, a total of 462 patients (311 patients in the parecoxib/valdecoxib group and 151 patients in the control group).

Treatment group assignment and power. Patients were randomized to one of the 2 treatment groups in a ratio of $2: 1$ for parecoxib/valdecoxib versus control treatment. The sample sizes of 300 patients in the group receiving intravenous $40 \mathrm{mg}$ of parecoxib/oral $40 \mathrm{mg}$ of valdecoxib and 150 patients receiving placebo were sufficient to detect a minimum difference of $12 \mathrm{mg}$ 
TABLE 1. Demographics of each treatment group

\begin{tabular}{|c|c|c|c|}
\hline & $\begin{array}{c}\text { Standard } \\
\text { of care, } \\
n=151(\%)\end{array}$ & $\begin{array}{c}\text { Parecoxib/valdecoxib } 40 \\
\text { mg IV/PO Q12H, } \\
n=311(\%)\end{array}$ & $P$ value \\
\hline Age (y) & & & $.223^{*}$ \\
\hline Mean \pm SD & $61.3 \pm 8.0$ & $60.3 \pm 8.2$ & \\
\hline Range & $41-75$ & $34-76$ & \\
\hline \multicolumn{4}{|l|}{ Sex } \\
\hline Male & $135(89)$ & $265(85)$ & $.215 \dagger$ \\
\hline Female & $16(11)$ & $46(15)$ & \\
\hline Country & & & $.998 \dagger$ \\
\hline United States & $56(37)$ & $114(37)$ & \\
\hline United Kingdom & $14(9)$ & $30(10)$ & \\
\hline Canada & $41(27)$ & $83(27)$ & \\
\hline Germany & $40(26)$ & $84(27)$ & \\
\hline $\mathrm{BMI}$ & & & $.037 \dagger$ \\
\hline$<30$ & $112(75)$ & $203(65)$ & \\
\hline$\geq 30$ & $38(25)$ & $108(35)$ & \\
\hline$\%$ Off pump & $21(14)$ & $30(10)$ & .21 \\
\hline
\end{tabular}

$I V$, Intravenous; $P O$, oral; $Q 12 H$, every 12 hours.

${ }^{*}$ ANOVA with treatment group and country as factors.

$\dagger \chi^{2}$ test.

in the average consumption of morphine between the 2 groups by using a 2-sided test at a $5 \%$ level of significance with $85 \%$ power. These sample sizes were sufficient to detect at least one occurrence of AEs of $1 \%$ incidence in the treatment group and $2 \%$ in the control group with $95 \%$ confidence and to compare individual $\mathrm{AE}$ rates of $1 \%$ versus $7 \%$ by using a 2 -sided test at a $5 \%$ level of significance with $80 \%$ power.

\section{Results}

\section{Characteristics of the Patients}

Between January 2000 and May 2000, 462 patients were enrolled and randomized to receive parecoxib/valdecoxib (311 patients) or standard therapy (control group, 151 patients). The population ranged in age from 34 to 76 years, with a mean age of 60.3 and 61.3 years in the parecoxib/ valdecoxib group (P/V group) and the control group, respectively (Table 1). Thirty-three percent of patients in the $\mathrm{P} / \mathrm{V}$ group and $38 \%$ of control patients were 65 years of age or older. There was no substantial difference between the preoperative characteristics or study group assignment among those patients who underwent surgical intervention with cardiopulmonary bypass versus those without cardiopulmonary bypass (Table 1). Except for a BMI of greater than $30 \mathrm{~kg} / \mathrm{m}^{2}(P=.037)$ and a trend toward increased prevalence of peripheral vascular disease $(P=.097)$ in the $\mathrm{P} / \mathrm{V}$ group (Tables 1 and 2), the proportion of patients with cardiac disease-related risk factors was similar between the $\mathrm{P} / \mathrm{V}$ and control groups (Table 2).

Of the 462 patients randomized to receive study medication, 26\% (118 patients) were withdrawn from the study after receiving at least one dose of study drug: $27 \%$ (84 patients) from the $\mathrm{P} / \mathrm{V}$ group and 23\% (34 patients) from the control group. The most frequent reasons for early withdrawal overall were AEs (15.6\%, 72 patients), protocol noncompliance $(7.8 \%, 36$ patients), treatment failure $(1.1 \%$, 5 patients), and protocol violations (0.9\%, 4 patients). Patients were observed for a mean of $12.5 \pm 4.8$ days. During the intravenous dosing period, patients in both treatment groups received an average of 6.6 doses. During the oral dosing period, patients in both groups received an average of 19.7 doses administered every 12 hours.

\section{Efficacy}

Primary efficacy measure: Morphine consumption. Morphine consumption by means of PCA after the initial administration of study medication was assessed during each 24-hour interval. The amount of morphine PCA used by patients in the $\mathrm{P} / \mathrm{V}$ group was significantly less than that in the control group for the periods from 0 to 24 hours $(P=$ $.015), 24$ to 48 hours $(P=.020)$, and 72 to 96 hours $(P=$ .023). Total morphine and total opioid (morphine equivalent) consumption at 24 hours was approximately $23 \%$ less in the $\mathrm{P} / \mathrm{V}$ group relative to the control group for morphine PCA $(P=.009$, Table 3$)$. In addition, significant cumulative reductions (approximately 20\% relative to control, $P=$ 0.039 ) were seen at 72 hours. By the 96- to 120-hour interval, only 3 patients were receiving morphine PCA.

Supportive efficacy measures. The mean peak pain intensity difference was significantly greater, indicating greater pain relief for COX-2 inhibitor treatment compared with control treatment on days 1 to $9(P=.015$, Figure 1$)$. A significantly greater $(P<.001)$ proportion of patients in the $\mathrm{P} / \mathrm{V}$ group rated the study medication as good or excellent (88\%-91\%) compared with control ratings of good or excellent (71\%-78\%) at all assessment periods, at intravenous to oral transition, at discharge from the hospital, and at the patient's final visit. Similarly, a greater proportion $(P<$ .001 ) of physicians rated parecoxib/valdecoxib treatment as good or excellent (88\%-90\%) compared with control treatment $(69 \%-74 \%)$ at each of the same assessment periods, and a smaller proportion $(P<.001)$ of physicians rated parecoxib/valdecoxib treatment as poor $(2 \%)$ compared with control treatment $(13 \%)$. As measured by the modified Brief Pain Inventory questionnaire, during oral therapy, there were significant reductions with parecoxib/valdecoxib treatment compared with control treatment in current pain (days 4-7), worst pain (days 4-9), average pain (days 4-8), mood (days 4-12), relations with others (days 4-12), sleeping (days 4, 5, 7, and 8), and walking (days 4 and 5).

\section{Safety}

Adverse events. AEs were reported in 89.4\% (135/151 patients) of control and $89.1 \%$ (277/31 patients) of P/V group patients during the study period $(P>.95$, Table 4$)$. 
TABLE 2. Patient characteristics of each treatment group

\begin{tabular}{|c|c|c|c|}
\hline Condition & $\begin{array}{l}\text { Standard of care, } \\
\mathrm{n}=151(\%)\end{array}$ & $\begin{array}{l}\text { Parecoxib/valdecoxib } 40 \mathrm{mg} \\
\text { IV/PO 012H, n = } 311(\%)\end{array}$ & $P$ value* \\
\hline Angina & & & .700 \\
\hline Current & $95(63)$ & $196(63)$ & \\
\hline History & $45(30)$ & $86(28)$ & \\
\hline Hypertension & & & .295 \\
\hline Current & $100(66)$ & $184(59)$ & \\
\hline History & $17(11)$ & $38(12)$ & \\
\hline Congestive heart failure & & & .619 \\
\hline Current & $4(3)$ & $6(2)$ & \\
\hline History & $2(1)$ & $8(3)$ & \\
\hline Atherosclerotic CVD & & & .457 \\
\hline Current & $121(80)$ & $248(80)$ & \\
\hline History & $5(3)$ & $18(6)$ & \\
\hline Myocardial infarction & & & .685 \\
\hline Current & $3(2)$ & $10(3)$ & \\
\hline History & $66(44)$ & $128(41)$ & \\
\hline Cerebrovascular ischemia & & & .595 \\
\hline Current & $0(0)$ & $0(0)$ & \\
\hline History & $7(5)$ & $18(6)$ & \\
\hline Peripheral vascular disease & $45(30)$ & $117(38)$ & .097 \\
\hline Diabetes mellitus & & & .746 \\
\hline Current & $29(19)$ & $69(22)$ & \\
\hline History & $1(1)$ & $2(1)$ & \\
\hline Tobacco use & & & .538 \\
\hline Current & $19(13)$ & $51(17)$ & \\
\hline History & $85(56)$ & $168(54)$ & \\
\hline
\end{tabular}

$I V$, Intravenous; $P O$, oral; $Q 12 H$, every 12 hours; $C V D$, Cardiovascular disease.

${ }^{*}$ Cochran-Mantel-Haenszel test stratified by country.

TABLE 3. Amount of total opioid (morphine equivalents) consumed during fixed time intervals in each treatment group

\begin{tabular}{|c|c|c|c|c|c|c|c|}
\hline \multirow[b]{2}{*}{ Time interval (h) } & \multicolumn{3}{|c|}{ Standard of care, $n=151(\mathrm{mg})$} & \multicolumn{3}{|c|}{$\begin{array}{c}\text { Parecoxib/valdecoxib } 40 \mathrm{mg} \mathrm{IV/PO} \\
\text { Q12H, n = } 311(\mathrm{mg})\end{array}$} & \multirow[b]{2}{*}{$P$ value } \\
\hline & $\mathbf{n}$ & Mean & SD & $\mathbf{n}$ & Mean & SD & \\
\hline $0-24$ & 123 & 25.4 & 24.3 & 251 & 19.7 & 18.7 & .009 \\
\hline 24-48 & 135 & 31.8 & 28.0 & 264 & 25.1 & 23.8 & .017 \\
\hline $48-72$ & 98 & 16.5 & 17.4 & 177 & 14.0 & 18.2 & .260 \\
\hline $72-96$ & 78 & 12.3 & 15.4 & 124 & 7.5 & 6.4 & .002 \\
\hline $96-120$ & 62 & 7.7 & 6.2 & 101 & 5.5 & 3.4 & .004 \\
\hline $120-144$ & 59 & 6.2 & 5.1 & 93 & 5.1 & 3.5 & .037 \\
\hline 144-168 & 53 & 6.7 & 4.0 & 79 & 5.6 & 4.0 & .098 \\
\hline
\end{tabular}

$P$ value was determined by means of 2-way ANOVA, with treatment and country as factors. $I V$, Intravenous; $P O$, oral; $Q 12 \mathrm{H}$, every 12 hours.

Pleural effusions, fever, bronchospasm, and tachycardia were seen with higher frequency in control patients, whereas supraventricular tachycardia and hypotension occurred more often in P/V group patients. AEs led to study withdrawal of $13.2 \%$ (20 patients) control and $16.7 \%$ (5 patients) $\mathrm{P} / \mathrm{V}$ group patients $(P=.412)$. Nausea $(2.0 \%$ of control and $2.6 \%$ of $\mathrm{P} / \mathrm{V}$ group patients, $P>.95)$ and vomiting $(2.0 \%$ of control and $1.6 \%$ of $\mathrm{P} / \mathrm{V}$ group patients, $P=.720)$, followed by a creatinine increase $(1.3 \%$ of control and $1.9 \%$ of $\mathrm{P} / \mathrm{V}$ group patients, $P>.95$ ), were the most common individual events that led to withdrawal from the study. Abnormalities in laboratory tests were common in both treatment groups but similar between groups. The incidence of renal dysfunction (as defined by a creatinine value $>2.0 \mathrm{mg} / \mathrm{dL}[177 \mu \mathrm{mol} / \mathrm{L}]$ and an increase of $>0.7$ $\mathrm{mg} / \mathrm{dL}[0.62 \mu \mathrm{mol} / \mathrm{L}]$ from baseline ${ }^{16}$ ) was $2.6 \%$ in both groups (P/V group, 8 patients; control group, 4 patients). Similar proportions $(P=.512)$ of patients in the $\mathrm{P} / \mathrm{V}$ group $(29.6 \%)$ versus the control group $(26.5 \%)$ received blood products, with mean transfusion requirements not differing $(P=.398)$ between groups (2.30 units per patient vs 2.55 units per patient, respectively). 


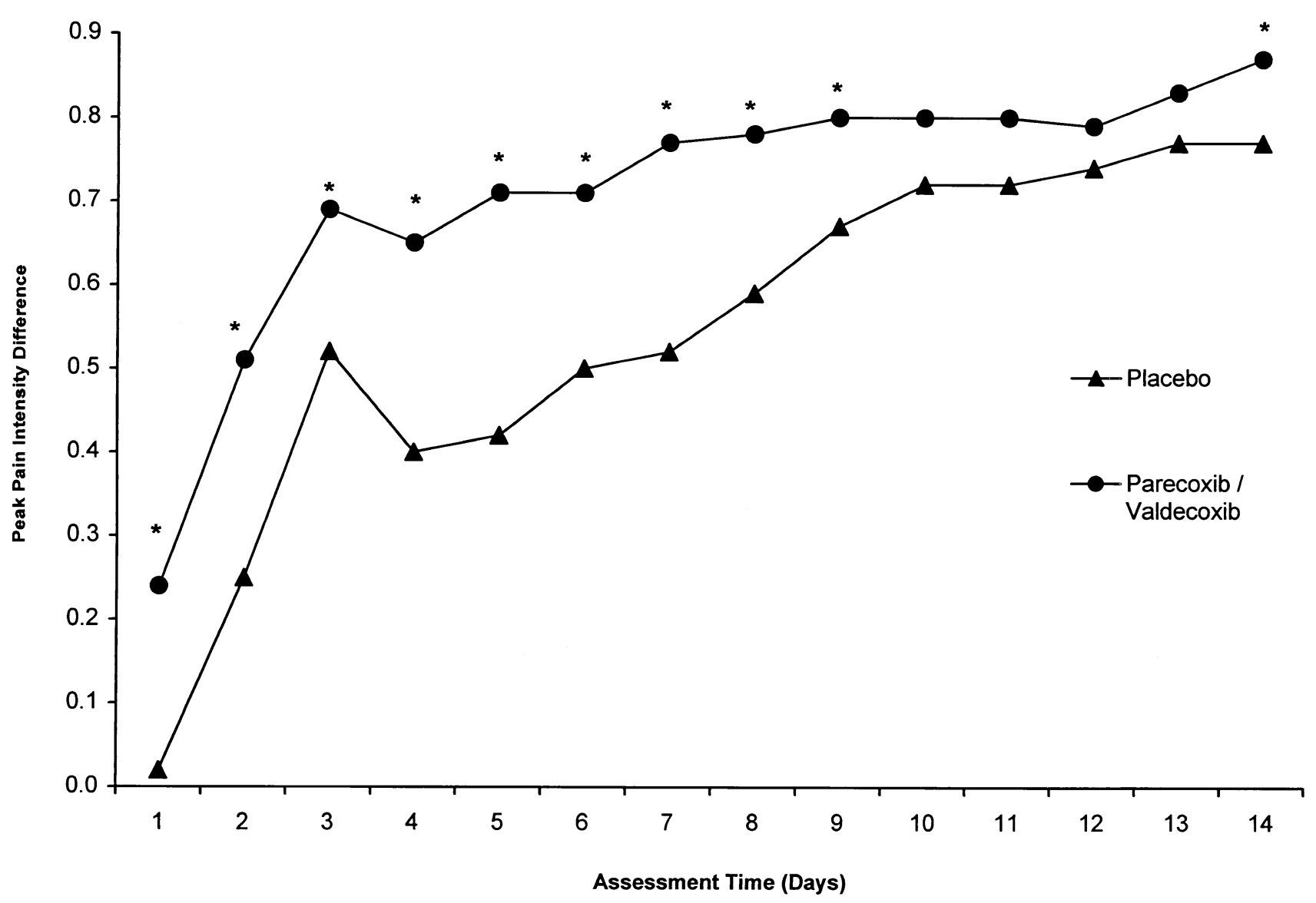

Figure 1. Peak pain intensity difference is defined as the reduction of peak pain intensity from baseline values. Higher values of peak pain intensity difference indicate less pain. ${ }^{*} \boldsymbol{P}<.050$ for analysis of covariance with treatment and country as factors and baseline pain intnsity as covariate.

Serious adverse events. The overall incidence of SAEs was $19 \%$ (116 events in 59 patients) in the $\mathrm{P} / \mathrm{V}$ group compared with $9.9 \%$ (26 events in 15 patients) in the control group $(P=.015$, Table 5$)$.

Four deaths occurred in the $\mathrm{P} / \mathrm{V}$ group versus zero in the control group $(P=.309)$. The causes of death were reported as myocardial infarction, cerebral infarction, pulmonary thromboembolism, and sternal wound infection.

Sternal wound infections occurred in $10(3.2 \%) \mathrm{P} / \mathrm{V}$ group patients versus zero patients in the control group $(P=$ .035). These were characterized by the investigators as 5 sternal wound infections, 2 deep sternal wound infections, 2 superficial sternal wound infections, and 1 sternal wound dehiscence caused by infection. Other than parecoxib/valdecoxib use, no other risk factor (eg, body mass) was associated with sternal wound infection.

Myocardial infarction was reported as an SAE in $1.6 \%$ (5/311) of P/V group patients versus $0.7 \%$ (1/151) of control patients $(P=.669)$. Four of the 5 myocardial infarctions in the $\mathrm{P} / \mathrm{V}$ group patients were given a diagnosis in the immediate perioperative period (within 24 hours of surgical intervention), whereas the other fifth occurred 14 days after the last dose of study medication.

Cerebrovascular complications occurred in $9(2.9 \%) \mathrm{P} / \mathrm{V}$ group patients versus $1(0.7 \%)$ patient in the control group $(P=.177)$. Risk factors significantly associated with occurrence of a cerebrovascular complication by means of stepwise logistic regression analysis included age of greater than 65 years (odds ratio $=8.15$ ), BMI of greater than 30 $\mathrm{kg} / \mathrm{m}^{2}$ (odds ratio $=7.18$ ), and history of cerebrovascular disease (odds ratio $=16.62$ ).

Renal events occurred in $6(1.9 \%) \mathrm{P} / \mathrm{V}$ group patients versus zero patients in the standard care group $(P=.184)$. None of these events required treatment with dialysis. Among $\mathrm{P} / \mathrm{V}$ group patients, a history of diabetes was significantly associated with development of a renal event $(P=.017)$. 


\section{Relationship to Study Medication}

Of the 116 events in the P/V group, 97 events were classified as not related to the study drug by the investigator, 19 were classified as having an uncertain relationship to the study drug, and 1 (renal function abnormality) was classified as probably related to the study drug. Regarding the control group, of the 26 events, 24 were classified as not related to the study drug, 2 as having an uncertain relationship to the study drug, and none as having a probable relationship to the study drug.

\section{Discussion}

\section{CABG Surgery and COX-2 Inhibition}

A number of factors, including the preoperative chronic disease state, the quality of anastamoses, the effectiveness of myocardial preservation, increased patient age, sex, and the need for emergency surgical intervention explain the serious morbidity after CABG surgery. ${ }^{16-18}$ Over the past several decades, significant gains in the management of patients undergoing coronary artery surgery have been achieved through improved intraoperative monitoring, myocardial preservation, and surgical technique. Advances have also been made in the area of pain control drugs. These include a variety of techniques (spinal opioids and local anesthetics) and drugs (natural and synthetic opioids, sedative-hypnotics, $\alpha_{2}$-adrenergic agonists, and NSAIDs). Ideally, these therapies provide not only patient comfort but also mitigation of untoward cardiovascular responses (hypertension, tachycardia, and myocardial ischemia), pulmonary responses (shunting and splinting), and other inflammatory and secondary sympathetic responses. ${ }^{2}$

However, as the age of patients undergoing CABG surgery increases, the prevalence of comorbid conditions will increase, and therefore therapies demonstrating reductions in untoward side effects will be desirable. Such therapies should facilitate early discharge or at least limit prolonged hospitalization for this population. Early ambulation is critical and will require more complete pain relief while preserving cognition. ${ }^{19}$ Use of opioids or sedatives-hypnotics will necessarily have to be limited. The use of NSAIDs, which profoundly affect the pain response yet have little effect on the sensorium (sedation, confusion, and disorientation), has been a major advance in the postoperative care of these patients. However, although effective, the initially developed nonselective NSAIDs (eg, ketorolac tromethamine [INN: ketorolac]) are associated with gastrointestinal ulceration and bleeding, antiplatelet effects, renal dysfunction, ${ }^{3,8-11}$ and, more recently, congestive heart failure, the latter of which was found to be more prevalent and severe in older patients. ${ }^{20-23}$ Nonetheless, despite these drawbacks, nonsteroidal anti-inflammatory agents have been recently studied for brief periods ( $<48$ hours) in managing postoperative pain after cardiac surgery. ${ }^{24-26}$
TABLE 4. AEs: Events occurring in at least $10 \%$ of patients in either treatment group or for which there was a difference $(P \leq .100)$ between groups

\begin{tabular}{lccc}
\hline Adverse event & $\begin{array}{c}\text { Standard } \\
\text { care, } \mathbf{n = 1 5 1} \\
(\%)\end{array}$ & $\begin{array}{c}\text { Parecoxib/ } \\
\text { valdecoxib, }\end{array}$ & \\
$\mathbf{n}=\mathbf{3 1 1}(\%)$ & $\boldsymbol{P}$ value \\
\hline Abnormal breath sounds & $21(13.9)$ & $44(14.1)$ & $>.95$ \\
Atrial fibrillation & $30(19.9)$ & $49(15.8)$ & .293 \\
Bronchospasm & $10(6.6)$ & $6(1.9)$ & .014 \\
Constipation & $56(37.1)$ & $116(37.3)$ & $>.95$ \\
Dizziness & $27(17.9)$ & $37(11.9)$ & .086 \\
Peripheral edema & $21(13.9)$ & $51(16.4)$ & .585 \\
Fatigue & $31(20.5)$ & $57(18.3)$ & .614 \\
Fever & $32(21.2)$ & $13(4.2)$ & $<.001$ \\
Hypotension & $9(6.0)$ & $41(13.2)$ & .024 \\
Insomnia & $23(15.2)$ & $59(19.0)$ & .365 \\
Nausea & $58(38.4)$ & $138(44.4)$ & .230 \\
Oliguria & $15(9.9)$ & $45(14.5)$ & .187 \\
Pleural effusion & $26(17.2)$ & $27(8.7)$ & .002 \\
Red blood cell disorders & $11(7.3)$ & $36(11.6)$ & .190 \\
Somnolence & $19(12.6)$ & $36(11.6)$ & .761 \\
SVT & $0(0.0)$ & $10(3.2)$ & .035 \\
Tachycardia & $22(14.6)$ & $22(7.1)$ & .017 \\
Vomiting & $17(11.3)$ & $43(13.8)$ & .466 \\
Anxiety & $14(9.3)$ & $15(4.8)$ & .060 \\
Rash & $4(2.6)$ & $2(0.6)$ & .092 \\
\hline P & &
\end{tabular}

$P$ value was determined with the Fisher exact test. $S V T$, Supraventricular tachycardia.

TABLE 5. SAEs occurring in more than 2 patients in either group

\begin{tabular}{lccc}
\hline & \multicolumn{3}{c}{$\begin{array}{c}\text { Current study } \\
\text { parecoxib/ } \\
\text { valdecoxib, }\end{array}$} \\
& $\begin{array}{c}\text { Standard care, } \\
\mathbf{n}=\mathbf{1 5 1}(\%)\end{array}$ & $\begin{array}{c}\mathbf{n}=\mathbf{3 1 1}(\%) \\
\text { Pny }\end{array}$ & $\boldsymbol{P}$ value* \\
\hline Any SA & $15(9.9)$ & $59(19.0)$ & .015 \\
Death & 0 & $4(1.3)$ & .309 \\
Cerebrovascular disorder & $1(0.7)$ & $9(2.9)$ & .177 \\
Myocardial infarction & $1(0.7)$ & $5(1.6)$ & .669 \\
Cardiac failure & $2(1.3)$ & $3(1.0)$ & .664 \\
Abnormal renal function & 0 & $6(1.9)$ & .184 \\
$\quad$ or increased & & & \\
$\quad$ creatinine level & & & \\
Gastrointestinal & 0 & $3(1.0)$ & .554 \\
$\quad$ hemorrhage & & & \\
Pleural effusion & $1(0.7)$ & $7(2.3)$ & .283 \\
Pneumonia & $3(2.0)$ & $4(1.3)$ & .688 \\
Sternal wound infection & 0 & $10(3.2) \dagger$ & .035 \\
Thrombophlebitis & 0 & $3(1.0)$ & .554 \\
\hline
\end{tabular}

*Fisher exact test.

tIncludes 5 sternal wound infections, 2 deep sternal wound infections, 2 superficial sternal wound infections, and 1 sternal wound dehiscence caused by infection.

However, other novel approaches have been sought, with the most recent being the selective inhibition of the COX-2 enzyme, thereby blocking inflammatory prostaglandin syn- 
thesis. The inducible form of this enzyme provides both analgesic and anti-inflammatory effects when inhibited. ${ }^{7,23,27}$ In contrast, inhibition of the constitutive COX-1 enzyme is associated with gastrointestinal, renal, and bleeding side effects. Because the efficacy of the COX-2 inhibitors celecoxib and rofecoxib, as well as parecoxib/valdecoxib, has been demonstrated in patients undergoing general surgery, we assessed the latter in higher-risk patients (ie, those with coronary artery disease undergoing revascularization). If effective and safe, then NSAID-associated gastrointestinal and platelet-associated complications might be circumvented, and other benefits might be gained by means of mitigation of the reperfusion-associated inflammatory response.

Because untoward pain responses after CABG surgery might last for several days, a COX-2 agent that could be administered both intravenously and orally was appealing.

\section{Efficacy Findings}

Our study was designed to compare a novel COX-2 inhibitor regimen (ie, intravenous parecoxib, followed by oral valdecoxib) to a control regimen that included PCA. Although a number of centers typically use a less-aggressive approach to pain control, we believed that such a stringent standard for the control group was appropriate because any new therapy should have efficacy exceeding that of the most aggressive pain control regimens. ${ }^{2}$ We found a statistically significant reduction in morphine PCA use in the P/V group for periods from 0 to 24 hours, 24 to 48 hours, and 72 to 96 hours. These findings were supported by the consistent reductions in the amount of total opioids consumed for each 24-hour period up to 168 hours, patient's perception of pain, physician's global assessment, and improvement in painrelated quality of life.

\section{Safety Findings}

Regarding safety, however, we found several results that raised concern. First, although the overall incidence of AEs was comparable in the 2 groups, significantly more patients in the $\mathrm{P} / \mathrm{V}$ group had SAEs than in the control group $(P=$ .015). Of specific concern is that the incidence of sternal wound infections was significantly greater in the $\mathrm{P} / \mathrm{V}$ group patients compared with that in control subjects (10/311 vs $0 / 151, P=.035)$. The effects of NSAIDS on sternal wound complications in the CABG surgical setting have not been previously reported. The COX-2 enzyme enables prostaglandin release and inflammatory response, and inhibition of this enzyme by nonspecific COX inhibitors (eg, NSAIDs), as well as specific COX-2 inhibitors (eg, parecoxib and valdecoxib), might impede reparative inflammatory responses and increase susceptibility to sternum infections. An alternative hypothesis is that the reduced rates for fever and tachycardia among P/V group patients might have delayed detection of an infection, resulting in further progression and greater consequence. Moreover, it should be considered that full-dose study drug administration was continued for a 2-week period in all P/V group patients, regardless of their need for analgesics, which might have contributed to increased susceptibility to or delayed recognition of infection. Regardless of mechanism, these safety issues merit careful consideration because of the importance of sternal complications in this setting, not only for NSAIDS and COX-2 inhibitors but also for any new medication that can impair normal inflammatory reparative processes.

Second, the incidence of both cardiovascular and cerebrovascular SAEs was proportionally, but not significantly, greater in $\mathrm{P} / \mathrm{V}$ group patients than in control patients, potentially implicating a thrombosis-mediated association with COX-2 inhibitor use. ${ }^{28}$ Nearly all of our patients underwent cardiac surgery with cardiopulmonary bypass and hypothermia. In such patients the delicate balance between platelets, endothelial cells, and serum clotting factors is disturbed, with a consequent thrombosis and clot lysis occurring disparately and unpredictably throughout the vascular system. Given that COX-2 inhibitors are platelet sparing, they might tip the balance toward thrombosis during periods of platelet activation. In addition, it has been argued that because COX-1 is unaffected, consequent release of thromboxane $\mathrm{A}_{2}$ further promotes platelet activation and thrombosis. Of note are 3 recently published analyses addressing this issue in chronically treated patients with arthritis. ${ }^{28,29}$ The first ${ }^{28}$ contrasted the results of the CLASS (celecoxib) and VIGOR (rofecoxib) clinical trials, with historical controls derived from the aspirin trials. Using a summary statistic, the authors emphasized the potential association between COX-2 inhibition and thrombogenic events (myocardial infarction, stroke, and vascular death). The second, ${ }^{29}$ in contrast, addressed a meta-analysis involving patients with both osteoarthritis and rheumatoid arthritis with respect to the use of rofecoxib versus placebo versus ibuprofen or diclofenac, finding no significant association among these groups for vascular events. In addition, a separate analysis of the CLASS study data found no increased risk of serious cardiovascular thrombotic events associated with celecoxib compared with naproxen and ibuprofen. ${ }^{30}$ Given that 4 of the 5 infarctions in this trial occurred perioperatively (ie, in close proximity to the administration of the first intravenous parecoxib/valdecoxib dose), if an association is inferred, then the acute intravenous administration of a COX-2 inhibitor must precipitate coronary artery thrombosis acutely (a hypothesis similar to that proposed by the recent work of Mukherjee et $\mathrm{al}^{28}$ ).

On the other hand, any extrapolation of the above chronic treatment regimens to treatment of acute pain in the perioperative setting must be made cautiously. Furthermore, 
it must be understood that arterial thrombosis after surgical revascularization might be precipitated by a number of other phenomena, including ${ }^{28,31-36}$ mechanically induced endovascular injury; acute reversal of heparin, precipitously increasing serum thrombin levels; concomitant use of antifibrinolytic agents (eg, aprotinin or episolon aminocaproic acid) to mitigate hemorrhage; instigation of a generalized inflammatory response, leading to platelet activation; and centralization of activated platelets. All are operative here, making it difficult if not impossible to discern an independent association between the study drug and thrombosis in our trial of a limited sample size. However, perhaps because patients likely received such aspirin not immediately on reperfusion but rather hours later, substantial platelet activation might have already occurred and precipitated a cascade leading to myocardial infarction and stroke. ${ }^{39}$ The observation that 4 of the 5 myocardial infarction events occurred within the immediate perioperative period is consistent with this hypothesis. Clearly, resolution of this important issue is necessary, particularly for higher-risk patients, such as ours.

Third, regarding the interaction between antifibrinolytic therapy use and COX-2 inhibitors, we found the following. Of the 311 patients receiving COX-2 inhibitors, 193 (62\%) also received antifibrinolytic therapy, and of these, 4 had either pulmonary embolism, myocardial infarction, thrombophlebitis, or arterial dissection versus $1,4,2$, and 0 patients, respectively, who received COX-2 inhibitors but did not receive antifibrinolytics. For the control group, one patient who received antifibrinolytics had one of these 4 complications versus no patients among those not receiving antifibrinolytics. Although there is no evidence of interaction, the numbers are small, and their significance must be assessed in a larger trial.

Fourth, the incidence of renal insufficiency in P/V group patients was proportionally greater than that for control patients, although the incidence of increased renal function test parameters was equal. Both COX-2 and COX-1 inhibition can be associated with impaired renal function. ${ }^{9}$ Given that even renal dysfunction without failure is associated with reduced survival and increased cost in these patients ${ }^{16}$ and given the possibility of a type I error, then the significance of this safety observation remains unresolved.

Finally, as with any new therapy, the cost-effectiveness must be assessed if the therapy has been proved effective and safe, and we will address such separately in the next trial.

\section{Limitations of the Current Study}

There are several limitations to the present study. First, our trial was marginally powered $(68 \%)$ to detect a 2 -fold difference (20\% vs $10 \%$ ) in SAEs between study groups and was not powered $(6 \%)$ to detect differences for specific SAEs. Moreover, the incidence of the SAEs in the control group patients was considerably lower than expected when compared with that reported in large-scale studies and clinical trials among similar patients (6\% for Q-wave infarction, $3 \%$ for stroke, and $7 \%$ for renal dysfunction). ${ }^{16,17,37}$ Consequently, a larger trial with equal numbers of patients in each treatment group is necessary to resolve these safety findings.

Second, several potentially important outcomes were not measured, such as chest tube output in the first 24 to 48 postoperative hours. Use of agents that are platelet sparing, such as COX-2 inhibitors, might mitigate blood loss in these patients, an effect not assessed in our trial.

Third, the control group actually received a nearly ideal standard of care (ie, analgesia in this clinical trial), given that they had ready access to morphine PCA and were closely observed for management of pain. Such a standard might be difficult to achieve in practice, especially given current efforts to limit postoperative resources. Consequently, one might speculate that even greater benefit can be realized with parecoxib/valdecoxib, given their ease of use.

Fourth, only a single dosage regimen and duration of parecoxib/valdecoxib was assessed. Considering that lower doses of parecoxib and valdecoxib also have been shown effective, ${ }^{4-6,38}$ then the potential to achieve the desired analgesic benefits with possibly lower risk of AEs with lower doses, shorter periods of administration, or both needs to be explored with future studies.

Fifth, we did not include a group receiving nonspecific NSAID agents, and therefore comparisons with such drugs in these patients cannot be surmised.

Sixth, regarding generalization, as for any clinical trial, inclusion and exclusion criteria can impose rather strict limits. Here, we estimate that our findings would be strictly applicable to approximately 220,000 patients or $30 \%$ of patients undergoing $\mathrm{CABG}$ with cardiopulmonary bypass annually throughout the world. Therefore caution should be exercised in the application of these findings to the entire CABG surgery population.

Finally, because of issues raised here, a follow-up trial should be designed to provide greater insight into the safety concerns and efficacy benefits in this population. In view of the limited power of this study, a larger trial will be needed to address relative frequency of uncommon events that might be associated with parecoxib/valdecoxib therapy.

\section{Conclusion}

The intravenous-oral parecoxib/valdecoxib regimen demonstrated superiority for pain relief over an aggressive therapeutic regimen supplemented with PCA. However, the higher incidence of SAEs observed with the parecoxib/ valdecoxib regimen, as well as the higher incidence of sternal infections, raise important concerns and mandate comprehensive evaluation in a large-scale trial before use in patients undergoing CABG surgery. 
We thank Ms Diane Beatty, Ms Brenda Xavier, and Mr Steven Kerkela of IREF for their technical assistance.

\section{References}

1. Mueller XM, Tinguely F, Tevaeaeari HT, Revelly JP, Chiolero R, Von Segesser LK. Pain location, distribution, and intensity after cardiac surgery. Chest. 2000;118:391-6.

2. Gust R, Pecher S, Gust A, Hoffmann V, Bohrer H, Martin E. Effect of patient-controlled analgesia on pulmonary complications after coronary artery bypass grafting. Crit Care Med. 1999;27:2218-23.

3. Garcia Rodriguez RL, Jick H. Risk of upper gastrointestinal bleeding and perforation associated with individual non-steroidal anti-inflammatory drugs. Lancet. 1994;343:769-72.

4. Daniels SE, Grossman EH, Kuss ME, Talwalker S, Hubbard RC. A double-blind, randomized comparison of intramuscularly and intravenously administered parecoxib sodium versus keterolac and placebo in a post-oral surgery pain model. Clin Ther. 2001;23:1018-31.

5. Camu F, Beecher T, Recker DP, Verburg KM. Valdecoxib, a COX-2 specific inhibitor, is an efficacious, opioid-sparing analgesic in patients undergoing hip arthroplasty. Am J Ther. 2002;9:43-51.

6. Desjardins P, Talwalker S. Preoperative administration of valdecoxib, a potent COX-2 specific inhibitor, provides effective postoperative analgesia. Anesthesiology. 2001;95:A-811.

7. Lipsky PE. Recommendations for the clinical use of cyclooxygenase2-specific inhibitors. Am J Med. 2001;110:3S-5S.

8. Buttgereit F, Burmester GR, Simon LS. Gastrointestinal toxic side effects of nonsteroidal anti-inflammatory drugs and cyclooxygenase2-specific inhibitors. Am J Med. 2001;110:13S-9S.

9. Whelton A. Renal aspects of treatment with conventional nonsteroidal anti-inflammatory drugs versus cyclooxygenase-2-specific inhibitors. Am J Med. 2001;110:33S-42S.

10. Catella-Lawson F, Crofford LJ. cyclooxygenase inhibition and thrombogenicity. Am J Med. 2001;110:28S-32S.

11. Hernandez-Diaz S, Garcia-Rodriguez LA. Epidemiologic assessment of the safety of conventional nonsteroidal anti-inflammatory drugs. Am J Med. 2001;110:20S-7S.

12. Wideman GL, Keffer M, Beaver WT. Analgesic eficacy of a combination of hydrocodone with ibuprofen in postoperative pain. Clin Pharmacol Ther. 1999;65:66-76.

13. Cleeland CS, Ryan KM. Pain assessment: global use of the brief pain inventory. Ann Acad Med. 1994;23:129-38.

14. Daut RL, Cleeland AS, Flannery RC. Development of the Wisconsin brief pain questionnaire to assess pain in cancer and other diseases. Pain. 1983; 17:197-210.

15. Edwards IR, Biriell C. Harmonisation in pharmacovigilance. Drug Safety. 1994;10:93-102.

16. Mora Mangano CT, Diamondstone LS, Ramsay JG, Aggarwal A, Herskowitz A, Mangano DT, et al. Renal dysfunction following myocardial revascularization: risk factors, adverse outcomes and hospital resource utilization. Ann Intern Med. 1998;128:194-203.

17. Roach GW, Kanchuger M, Mora Mangano CT, Newman MF, Nussmeier NA, Wolman R, et al. Adverse cerebral outcomes after coronary bypass surgery. N Engl J Med. 1996;335:1857-63.

18. Kennedy JW, Kaiser GC, Fisher LD. Multivariate discriminant analysis of the clinical and angiographic predicators of operative mortality from the collaborative study in coronary artery surgery (CASS). J Thorac Cardiovasc Surg. 1980;80:876-87.

19. Weissman C. Pulmonary function after cardiac and thoracic surgery. Anesth Analg. 1999;88:1272-9.

20. Kehlet H, Dahl JB. The value of "multimodal" or "balanced analgesia" in postoperative pain treatment. Anesth Analg. 1993;77:1048-56.

21. Heerdink ER, Leufkens HG, Herings RM, Ottervanger JP, Stricker $\mathrm{BH}$, Bakker A. NSAIDS associated with increased risk of congestive heart failure in elderly patients taking diuretics. Arch Intern Med. 1998;158:1108-12.

22. Page J, Henry D. Consumption of NSAIDS and the development of congestive heart failure in elderly patients: an underrecognized public health problem. Arch Intern Med. 2000;160:777-84.

23. Gibson FA. Reduce dose of NSAIDS in the elderly. Br J Anaesth. 1999;81:369-72.
24. Hynnienen MS, Cheng DC, Hossian IJ, Carroll J, Aumbhagavan SS, Yue R, et al. Non-steroidal anti-inflammatory drugs in treatment of postoperative pain after cardiac surgery. Can J Anaesth. 2000;47: $1182-7$.

25. Rapanos T, Murphy P, Szalai JP, Burlacoff L, Lam-McCulloch J, Kay J. Rectal indomethacin reduces postoperative pain and morphine use after cardiac surgery. Can J Anaesth. 1999;46:725-30.

26. Lin JC, Swerc MF, Magovern JA. Non-steroidal anti-inflammatory drug-based pain control for iminimally invasive direct coronary artery bypass surgery. Heart Surg Forum. 1999;2:169-71.

27. Cannon GW, Breedveld FC. Efficacy of cyclooxygenase-2-specific inhibitors. Am J Med. 2001;110:6S-12S.

28. Mukherjee C, Nissen SE, Topol EJ. Risk of cardiovascular events associated with selective COX-2 inhibitors. JAMA. 2001;286:954-9.

29. Marvin KA, Weir MR, Reicin A. Cardiovascular thrombotic events in controlled, clinical trials of rofecoxib. Circulation. 2001;104:2280-8.

30. White WB, Faich G. Celecoxib, a cyclooxygenase-2 specific inhibitor, is not associated with an increased risk of pro-thromboembolic events. Am J Cardiol. 2002;89:425-30.

31. Lichenstein SV, Ashe KA, el Dalati H, Cusimano RJ, Panos A, Slutsky AS. Warm heart surgery. J Thorac Cardiovasc Surg. 1991; 101:269-74.

32. Yau TM, Weisel RD, Mickle DA, Komeda M, Ivanov J, Carson S, et al. Alternative techniques of cardioplegia. Circulation. 1992;86:II37784.

33. Julia PL, Buckberg GD, Acar C, Partington MT, Sherman MP. Studies of controlled reperfusion after ischemia. XXI. Reperfusate composition: superiority of blood cardioplegia over crystalloid cardioplegia in limiting reperfusion damage. Importance of endogenous oxygen free radical scavengers in red blood cells. J Thorac Cardiovasc Surg. 1991;101:303-13.

34. Herskowitz A, Mangano DT. The inflammatory cascade: a final common pathway for perioperative injury? Anesthesiology. 1996;85:95760.

35. The Antithrombotic Trialists' Collaboration. Collaborative meta-analysis of randomised trials of antiplatelet therapy for prevention of death, myocardial infarction, and stroke in high risk patients. $B M J$. 2002;324:71-86.

36. Chesebro JH, Fuster V, Elveback LR, Clements IP, Smith HC, Holmes DR Jr, et al. Effect of dipyridamole and aspirin on late vein-graft patency after coronary bypass operations. N Engl J Med. 1984;310: 209-14.

37. Mangano DT for the McSPI Research Group. Effects of acadesine on myocardial infarction, stroke and death following surgery: a metaanalysis of the five international randomized trials. JAMA. 1997;277: 325-32.

38. Jain KK. Evaluation of intravenous parecoxib for the relief of acute post-surgical pain. Expert Opin Investig Drugs. 2000;9:2717-23.

39. Mangano DT. Aspirin and mortality from coronary bypass surgery. $N$ Engl J Med. 2002;347:1309-17.

\section{Appendix 1 \\ Analysis Group/Ischemia Research and Education \\ Foundation}

Director, McSPI Research Group

Dennis T. Mangano, $\mathrm{MD}, \mathrm{PhD}$

Quality Assurance

Carolyn Dudek, RN

Analysis Coordination

Dan Canafax, PharmD

William Spickler, MD, PhD

Laurie Carlson, RN

Juliet Li, MD

Camelia Dumitrescu, MD

Susan Owen, RN

Kathleen Luden

Analysis Group 
Ping Hsu, PhD

David Kardatzke, $\mathrm{PhD}$

Nick Paszty

\section{Electrocardiographic Analysis}

Polina Voloshko, MD

Adam Zhang, MD

Ricardo Dea, MD

Lucy Zhu, MD

Margarita Savina, MD

\section{Appendix 2}

The cohort of the McSPI Research Group, who participated in this study. These investigators are listed in alphabetical order with their medical centers.

Keith Allen, MD, St Vincent Hospital, Indianapolis, Ind Peter Alston, MD, Royal Infirmary, Edinburgh, Scotland Prasad Atluri, MD, VA Medical Center, Houston, Tex

Elliott Bennett-Guerrero, MD, Columbia Presbyterian Medical Center, New York, NY

Steven Boyce, MD, Washington Hospital Center, Silver Spring, $\mathrm{Md}$

David Bronheim, MD, The Mt Sinai Medical Center, New York, NY

Edward Busse, MD, Regina General Hospital, Regina, Canada Jean Bussieres, MD, Laval Hospital, Sainte-Foye, Canada Marguerita Camacho, MD, Montefiore Medical Center, Bronx, NY

Maria Chakerian, MD, Bay Area Center for Pain \& Palliative Care, Los Gatos, Calif

Davy Cheng, MD, Toronto General Hospital, Toronto, Canada

Colm Cole, MD, St Paul's Hospital, Vancouver, Canada

Paul Dlabal, MD, Cycle Solutions, Inc, Austin, Tex

Roger Dreiling, MD, Corvalis Clinic, Corvalis, Ore

Peter Duke, MD, University of Manitoba, Winnipeg, Canada

Jean-Yves Dupuis, MD, University of Ottawa Heart Institute, Ottawa, Canada

Michael Eaton, MD, University of Rochester Medical Center, Rochester, NY

Jeffrey Everett, MD, University of Iowa, Iowa City, Iowa

Rob Feneck, MD, St Thomas Hospital, London, United Kingdom Andreas Fiehn, MD, Klinikum Kassel, Kassel, Germany

Barry Finnegan, MD, University of Alberta, Edmonton, Canada

Michael Fiocco, MD, Union Memorial Hospital, Silver Spring, Md

Jane Fitch, MD, Baylor College of Medicine, Houston, Tex

Manuel Fontes, MD, New York Presbyterian (Cornell), New York, NY

Mark Fox, MD, Cardiothoracic Centre, Liverpool, United Kingdom

Susan Garwood, MD, Yale University, New Haven, Conn

George Gordon, MD, New England Medical Center, Boston, Mass

Michael Grave, MD, Long Island Jewish Hospital, New Hyde Park, NY

Richard Hall, MD, QE II Health Sciences Center, Halifax, Canada

Kenneth Hanger, MD, Roper Care Alliance Hospital, Mt Pleasant, $\mathrm{SC}$

Charles Hantler, MD, University of Texas Health Sciences Center, San Antonio, Tex
Gunter Hempelmann, MD, Justus-Liebig University, Giessen, Germany

William Higgs, MD, Gulf Coast Clinical Services, Inc, Mobile, Ala

Andreas Hoeft, MD, University of Bonn, Bonn, Germany

Charles Hogue, MD, Washington University, St Louis, Mo

Mitchell Jacobs, MD, North Shore University Hospital, Manhasset, NY

Shubjeet Kaur, MD, University of Massachusetts Memorial Health Center, Worcester, Mass

Hurley Knott, MD, SORRA Research, Birmingham, Ala

Dan Kopacz, MD, Virginia Mason Medical Center, Seattle, Wash

Michael Koren, MD, Jacksonville Center for Clinical Research, Jacksonville, Fla

John Laschinger, MD, Sinai Hospital of Baltimore, Silver Spring, Md

John Leslie, MD, Mayo Clinic Hospital, Phoenix, Ariz

Stephen Lincoln, MD, St Joseph's Medical Center, Silver Spring, Md

Phil Malan, MD, University of Arizona, Tucson, Ariz

Eike Martin, MD, University of Heidelberg, Heidelberg, Germany

Raymond Martineau, MD, Montreal Heart Institute, Montreal, Canada

Joseph Mathew, MD, Duke University Medical Center, Durham, NC

David Mazer, MD, St Michael's Hospital, Toronto, Canada

Richard McLean, MD, Hamilton Health Sciences Corp, Hamilton, Canada

Stan Mogelnicki, MD, St Joseph's Hospital, Atlanta, Ga

Chris Mora Mangano, MD, Stanford University Medical Center, Stanford, Calif

Lars Newsome, MD, Scripps Memorial Hospital, La Jolla, Calif Nancy Nussmeier, MD, Texas Heart Institute, Houston, Tex

Elisabeth Ott, MD, University of Munich, Munich, Germany

James Park, MBChB, South Cleveland Hospital, Middlesbrough, United Kingdom

Eric Pierce, MD, Boston University Medical Center, Boston, Mass

Evan Pivalizza, MD, Hermann Hospital, University of Houston, Houston, Tex

Joseph Quinlan, MD, University of Pittsburgh, Pittsburgh, Pa

Fiona Ralley, MD, University of Western Ontario, London, Canada

James Ramsay, MD, Emory University Hospital, Atlanta, Ga

Lowell Reynolds, MD, Center for Pain Management, Loma Linda Medical Center, Loma Linda, Calif

Gary Roach, MD, Kaiser Foundation Hospital, San Francisco, Calif

Louis Samuels, MD, Hahnemann University Hospital, Philadelphia, $\mathrm{Pa}$

Jens Scholz, MD, University Hospital Eppendorf, Hamburg, Germany

Ketan Shevde, MD, Maimonides Medical Center, Brooklyn, NY

David Smith, MD, Southhampton General Hospital, Southhampton, United Kingdom

Hans Sonntag, MD, University of Goettingen, Goettingen, Germany 
Bruce Spiess, MD, Medical College of Virginia, Richmond, Va Ethan Stein, MD, Mary Washington Hospital, Silver Spring, Md Louis Suarez, MD, Appleton Medical Center, Appleton, Wis

Steven Timmis, MD, William Beaumont Hospital, Royal Oak, Mich James Todd, MD, Peninsula Regional Medical Center, Silver Spring, Md

Bruce Toporoff, MD, Southwest Clinical Research, Inc, Phoenix, Ariz

Mark Trankina, MD, Shands Hospital University of Florida, Gainesville, Fla

Hamed Umedaly, MD, University of British Columbia, Vancouver, Canada

Hugo Van Aken, MD, University of Muenster, Muenster, Germany
Joseph Van DeWater, MD, Medical Center of Central Georgia, Macon, $\mathrm{Ga}$

Eugene Viscusi, MD, Thomas Jefferson University Hospital, Philadelphia, $\mathrm{Pa}$

Timothy Votapka, MD, Evanston Northwestern Healthcare, Evanston, Ill

Alain Vuylsteke, MD. Papworth Hospital NHS Trust, Cambridge, United Kingdom

Mark Wallace, MD, University of California, San Diego, La Jolla, Calif

Herb Ward, MD, VA Medical Center Surgical Services, Minneapolis, Minn

David Whitaker, MD, Manchester Royal Infirmary, Manchester, United Kingdom 